\title{
Prediction of the progression of joint space narrowing in osteoarthritis of the knee by bone scintigraphy
}

\author{
Paul Dieppe, Janet Cushnaghan, Philip Young, John Kirwan
}

\begin{abstract}
Objectives-To test the hypothesis that bone scintigraphy will predict the outcome of osteoarthritis (OA) of the knee joint.

Methods-Ninety four patients (65 women, 29 men; mean age $64 \cdot 2$ years) with established OA of one or both knee joints were examined in 1986, when radiographs and bone scan images (early and late phase) were also obtained. The patients were recalled, re-examined, and had further radiographs taken in 1991. Paired entry and outcome radiographs were read by a single observer, blinded to date order and other data. Scan findings and other entry variables were related to outcome. Progression of OA of the knee was defined as an operation on the knee or a decrease in the tibiofemoral joint space of $2 \mathbf{~ m m}$ or more.
\end{abstract}

Results-Over the five year study period 10 patients died and nine were lost to follow up. Fifteen had an operation on one or both knees ( 22 knees). Of the remaining 120 knees (60 patients) analysed radiographically, $14(12 \%)$ had progressed in the manner defined. Of 32 knees with severe scan abnormalities, $28(88 \%)$ showed progression, whereas none of the 55 knees with no scan abnormality at entry progressed. The strong negative predictive power of scintigraphy could not be accounted for by disease severity or any combination of entry variables. Pain severity predicted a subsequent operation, but age, sex, symptom duration, and obesity had no predictive value.

Conclusions-Scintigraphy predicts subsequent loss of joint space in patients with established $O A$ of the knee joint. This is the first description of a powerful predictor of change in this disease. The finding suggests that the activity of the subchondral bone may determine loss of cartilage.

(Ann Rheum Dis 1993; 52: 557-563)

It has been estimated that between 3 and 5\% of the adult population is affected by osteoarthritis (OA) of the knee joint. ${ }^{1}$ This disorder is one of the principal causes of pain and disability in older people. ${ }^{2}$ The outcome and impact of OA of the knee varies greatly between subjects, however. In many patients it apparently stabilises and symptoms may improve with time ${ }^{34}$; in others, joint damage progresses leading to severe pain and disability requiring an operation. ${ }^{56}$

Osteoarthritis is a slowly evolving disorder of synovial joints in which a complex combination of degradative and reparative processes alters the anatomy and matrix composition of the articular cartilage and subchondral bone. ${ }^{7}$ Aetiological factors include age, sex, and other systemic influences, as well as local biomechanical forces acting on the joint. ${ }^{8}$ Relatively little is known about which of the aetiological factors and disease processes control progression or determine the great heterogeneity of outcome, ${ }^{89}$ though it has been suggested that subchondral bone activity may be important $^{10}$ and bone scans have been shown to have predictive value in OA of the hand. ${ }^{11} 12$

The detection of variables which predict the outcome of OA of the knee is desirable for two reasons: first, it would be of clinical value to be able to delineate those subjects who have a high or low risk of developing severe disease; secondly, it would help unravel which aspects of the disease processes are the most important in progression, perhaps leading to strategies for treatment.

The study reported here was designed to test the hypothesis that subchondral bone activity as detected by scintigraphy ${ }^{13}$ will predict subsequent change in OA of the knee defined as progression to an operation or a loss of tibiofemoral joint space of $\geqslant 2 \mathrm{~mm}$ on the radiographs. In addition, the data have been examined for any other demographic or clinical findings that might predict the progression of OA of the knee.

\section{Patients and methods}

\section{SUBJECTS}

One hundred patients referred to a hospital based rheumatology unit entered the study. Each patient was diagnosed as having OA of one or both knees using the following criteria: use related knee pain with radiographic features of OA of the same joint, including the presence of definite osteophytes or narrowing of the joint space, or both. All subjects were subsequently referred to a specialist clinic where they were interviewed and examined by a single observer as described elsewhere. ${ }^{13}$

Royal Infirm

United Kingdom.

Accepted for publication 28 April 1993 


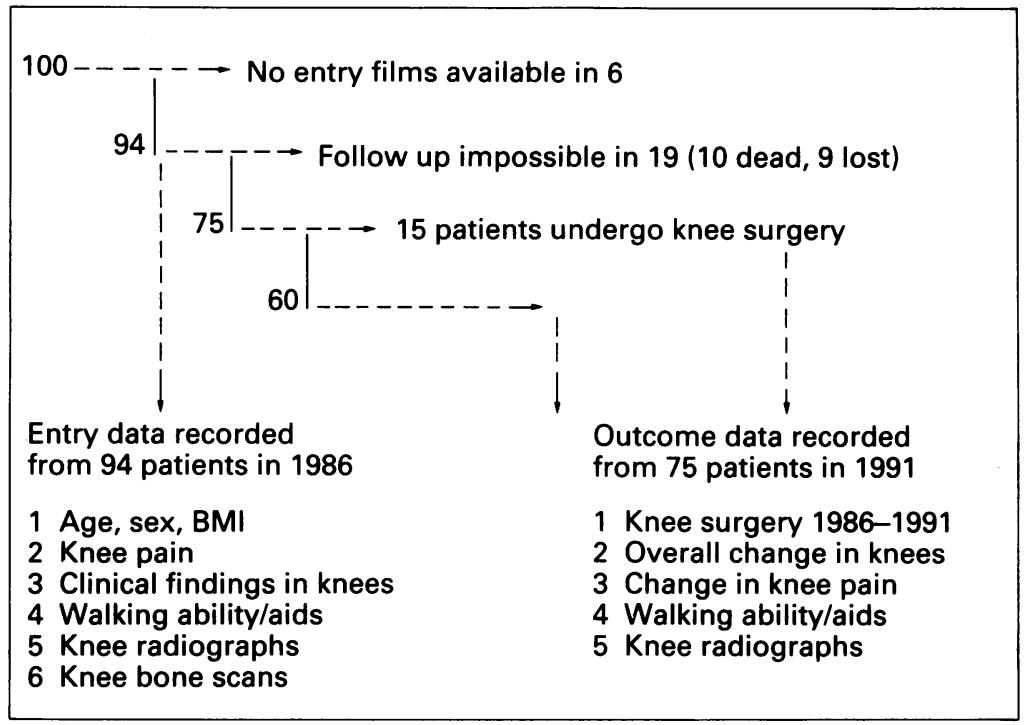

Overall design and outcome of the study. BMI=body mass index.

Radiographs and bone scans of both knees were obtained at entry to the study during 1986. A planned five year review was carried out in 1991. A review of the entry data showed that there were insufficient data from baseline radiographs or scans in six patients and they were excluded from the study. An attempt was made to contact the remaining 94 to reinterview and examine them; and to obtain a second set of radiographs (figure).

\section{ENTRY DATA}

Demographic data obtained in 1986 included age, sex, height, and weight. The subjects were asked about the duration of symptoms in each knee and the severity of current use related pain (none, mild, moderate, or severe). The presence or absence of crepitus, bony swelling, soft tissue swelling, and instability of the collateral ligaments in each knee was recorded. Lower limb disability was assessed by recording the use of walking aids and an estimate of walking ability on a five point scale (none, housebound, major impairment, minor difficulty, normal). Two plain radiographs of each knee were obtained, an anteroposterior standing view in full extension and a lateral taken in $30^{\circ}$ of flexion. Bone scan images of each knee were also obtained as described elsewhere. ${ }^{13}$ Briefly, gamma camera images were obtained three to five minutes (anteroposterior view only) and three to four hours (anteroposterior and lateral) after the intravenous injection of $600 \mathrm{MBq}$ of diphosphonate labelled with technetium-99m.

OUTCOME DATA

At review in 1991 the knee pain and lower limb disability was assessed as before. Patients were also asked to say whether they thought each knee was the same, better, or worse than in 1986. The main outcome measures used were the need for a major operation to the knee in the intervening five years and change in the radiographic appearances of each knee. We chose a primary definition of deterioration as either an operation on the knee joint or a reduction in tibiofemoral interbone distance of $\geqslant 2 \mathrm{~mm}$. Patients were therefore asked about any operations, their knees were examined, and the radiographs repeated using exactly the same technique as in 1986.

RADIOGRAPHIC SCORING

All radiographs from the two time points were collected and the date and patient identifications were masked with tape and replaced by a random code number. One observer (PD) then scored all radiographs using a combination of two techniques described elsewhere. ${ }^{14}{ }^{15} \mathrm{~A}$ visual scoring of osteophytes $(0,1,2)$ and subchondral bone sclerosis $(0,1)$ in each of the three major compartments (medial, lateral, and patellofemoral) was recorded. ${ }^{14}$ In addition, the interbone distance of the medial and lateral tibiofemoral compartments was measured in millimetres at the mid point. ${ }^{15}$ Paired films (1986 and 1991) of each patient were presented in a random order and the observer was also asked to record any differences between them (none, or some change, with a brief description).

\section{ASSESSMENT OF SCANS}

The scan images obtained from these patients at entry to the study have been reported previously. ${ }^{13}$ For the purposes of this study, all the scans were reassessed by a single observer (PD) who was blinded to patient identification and radiographic findings. Abnormal isotope retention at each knee was recorded as present or absent on the early (perfusion phase) scans. Focal areas of uptake in the later bone phase were recorded in more detail. The compartment involved and pattern of uptake (confined to the joint margin or extending deep into the subchondral bone) were noted.

STATISTICAL ANALYSIS AND MISSING DATA

The major use of statistics in this paper is descriptive, either in terms of observed frequencies, or means and standard errors. The significance of any associations between pairs of variables has also been sought, however, using a variety of standard techniques. If both variables were continuous then the association was based on the product moment correlation coefficient. ${ }^{16}$ If either or both variables were categorical, but ordered and had three or more categories (these were use pain, walking aids, and walking ability) then their ranks ${ }^{16}$ were used instead of the actual values to form a ranked correlation coefficient. ${ }^{16}$ If the two variables were categorical but were either unordered or binary then the measures of association were based on the Pearson $\chi^{2}$ test. ${ }^{16}$ If one variable was continuous and the other was either unordered categorical or binary then a one way analysis of variance ${ }^{16}$ was used to test the significance of the association. This reduces to a $t$ test for a binary variable. If one variable was unordered categorical and the 
other ordered categorical then a KruskalWallis ${ }^{17}$ test was used to assess the significance of any association. This reduces to a MannWhitney $U$ test $^{16}$ for the binary variable. All continuous variables (body mass index, age, duration of symptoms, interbone distance, both medial and lateral) were checked (and passed) for normality using a Shapiro-Wilks test. ${ }^{17}$

Patients lost to follow up between the initial and five year visits could not be included in any zero to five year comparison. If an individual measurement was missing then the analysis was completed on the available data. The overall amount of missing data was small $(<5 \%)$ but spread throughout the patients so that omitting those patients without complete data would have been unattractive and illogical as the missing data appear to be missing at random.

Discriminant analysis was used to access if the scan could be predicted from either the clinical or radiological variables. This is equivalent to using multiple regression with a categorical dependent variable. ${ }^{17}$

\section{Results}

The 94 subjects (65 women, 29 men) had a mean (SD) age of $64 \cdot 2(11 \cdot 6)$ years at entry to the study in 1986 . Their body mass index ${ }^{18}$ was calculated from recorded height and weight; the mean(SD) was $26 \cdot 2(5 \cdot 1)$ and $25(27 \%)$ had a body mass index of 30 or more and were categorised as obese. Table 1 gives the main clinical findings at entry. Osteoarthritis of the knee (as defined above) was bilateral in $52(55 \%)$ patients. Seventy two $(77 \%)$ of 94 subjects had some limitation of walking ability

\section{Table 1 Clinical findings at entry to the study}

\begin{tabular}{lc}
\hline Clinical findings in individual knees ( $\mathrm{n}=188)$ & \\
Mean (SD) duration of symptoms (years) & $9 \cdot 0(11 \cdot 5)$ \\
Current use related pain (\%) & 30 \\
None & 27 \\
Mild & 14 \\
Moderate & 29 \\
Severe & 64 \\
Crepitus (\%) & 48 \\
Bony swelling (\%) & 52 \\
Soft tissue swelling (\%) & 15 \\
Collateral ligament instability (\%) & \\
Lower limb disability in individual subjects (n=94) & \\
Use of walking aids (\%) & \\
None & 57 \\
One stick & 33 \\
Two sticks & 4 \\
Frame & 5 \\
Walking ability (\%) & 0 \\
None & 21 \\
Housebound & 28 \\
Severe impairment & 28 \\
Mild limitation & 23 \\
Normal & \\
\hline
\end{tabular}

and $40(43 \%)$ were using walking aids. One hundred and forty two (76\%) of 188 knees were causing pain at entry. One hundred and nineteen $(70 \%)$ of 171 knees had some abnormal physical signs, but only $27(23 \%)$ of these had ligamentous instability.

Table 2 gives the main radiographic and scintigraphic abnormalities recorded from the entry films. At least one radiographic feature of OA was seen in $124(66 \%)$ of medial compartments, $78(41 \%)$ of lateral compartments, and $133(71 \%)$ of patellofemoral joints. Tricompartmental OA was present in $44(23 \%)$ knees, the remainder had one $(26(14 \%))$ or two compartments (44 (23\%)) affected, the most common pattern being medial and patellofemoral joint disease alone or in combination. Forty five $(24 \%)$ knees had an abnormal perfusion phase scan and $121(64 \%)$ showed an abnormality on the bone phase. The most common pattern of bone phase scan abnormality was a rim pattern confined to one $(92(61 \%)$ knees) or two $(27(18 \%))$ compartments.

The figure summarises the overall outcome of the study. During the five year period 19 patients were lost to follow up; 10 had died and nine were either unwilling to comply or could not be traced. A total of 75 patients were reexamined in 1991, 15 of whom had had an operation on one or both knees ( 22 knees operated on); progression to an operation was regarded as one of the main outcomes. The remaining 60 patients were reassessed clinically. Walking ability was worse in 26 patients, the same in 27 , and had improved in five. In 199127 were using a walking aid, compared with 17 of these 60 patients in 1986. Symptoms in individual knees were reported to be worse in 34, the same in 42 and better than before in 41 of the 120 knees examined.

A comparison of entry data from the 19 patients lost to follow up, the 15 who had an operation, and the 60 who were fully reviewed after five years was undertaken (table 3 ). The only significant differences found were that patients who had died or were lost to follow up were older than the other two groups at entry and were mainly women. In addition, the group who had an operation had higher body mass index, though their mean was still just below 30. The two groups of dead/lost patients and surgery patients used more walking aids on average and had shorter walking distances than the remaining patients, though the surgery and dead/lost groups were not different from each other.

Table 2 Radiographic and scintigraphic abnormalities in the different knee compartments at entry to the study (188 knees)

\begin{tabular}{lcccc}
\hline & $\begin{array}{l}\text { Medial } \\
\text { compartment }\end{array}$ & $\begin{array}{l}\text { Lateral } \\
\text { compartment }\end{array}$ & $\begin{array}{c}\text { Patellofemoral } \\
\text { compartment }\end{array}$ & $\begin{array}{l}\text { Whole } \\
\text { knee }\end{array}$ \\
\hline $\begin{array}{l}\text { Median interbone distance in mm (lower quartile) } \\
\text { Patellofemoral joint space narrowing }\end{array}$ & $5(3)$ & $5(4)$ & - & - \\
Osteophytes (No(\%)) & - & - & - \\
Subchondral bone sclerosis (No(\%)) & $120(64)$ & $121(64)$ & $130(69)$ & - \\
Chondrocalcinosis (No(\%)) & $100(48)$ & $58(31)$ & $113(60)$ & - \\
Abnormal isotope retention: perfusion phase (No(\%)) & - & - & - & $41(22)$ \\
Abnormal isotope retention (No(\%)) & - & - & $54(24)$ \\
Bone phase & $67(36)$ & $31(17)$ & $29(13)$ & $121(64)$ \\
Rim pattern & $50(27)$ & $27(14)$ & $28(38)$ \\
Extended pattern & $17(9)$ & $4(2)$ & $28(15)$ & $49(26)$ \\
\hline
\end{tabular}


Table 3 Comparison of entry data in patients lost to follow up, those who had an operation, and the remainder of the group

\begin{tabular}{llll}
\hline Entry data & $\begin{array}{l}\text { Patients } \\
\text { dead or lost } \\
\text { to follow up } \\
(n=19)\end{array}$ & $\begin{array}{l}\text { Patients } \\
\text { having an } \\
\text { operation } \\
(n=15)\end{array}$ & $\begin{array}{l}\text { Patients fully } \\
\text { reviewved in } \\
1991 \\
(n=60)\end{array}$ \\
\hline Mean (SE) age (years) & $72 \cdot 6(2 \cdot 3)$ & $60 \cdot 9(2 \cdot 6)$ & $62 \cdot 2(1 \cdot 5)$ \\
Sex (F:M) & $18: 1$ & $8: 7$ & $39: 21$ \\
Mean (SE) BMI & $24 \cdot 6(1 \cdot 0)$ & $29 \cdot 2(1 \cdot 3)$ & $25 \cdot 9(0 \cdot 7)$ \\
Using walking aids (n) & 13 & 10 & 17 \\
Reduced walking ability (n) & 14 & 12 & 21 \\
\hline
\end{tabular}

${ }^{\star} \mathrm{BMI}=$ Body mass index.

Apart from a knee operation, the main outcome for the purpose of this study was the change in radiographic features of $\mathrm{OA}$ in individual knees over the five year period of observation. Of the 75 patients available for review, 15 had had an operation on the knee, with 22 knees being operated on, leaving eight contralateral unoperated knees for observation. These eight knees have been omitted from analysis because of the possible effect of a unilateral operation on the contralateral knee joint. The analysis of radiographic outcome was therefore confined to the 120 knees of the 60 remaining patients who had not had an operation. The number of knees showing a change in the various radiographic features in these 60 patients is shown in table 4 . Most of the recorded change was in the tibiofemoral joint space.

Table 4 Change in radiographic features of osteoarthritis of the knee in the 60 patients available for five year follow $u p$, and in whom no knee operation was performed

\begin{tabular}{lc}
\hline Radiographic feature & $\begin{array}{c}\text { Number (\%) of knees } \\
\text { showing change }(n=120)\end{array}$ \\
\hline Osteophytosis & $24(20)$ \\
Subchondral bone sclerosis & $21(18)$ \\
Patellofemoral joint space & $5(4)$ \\
Observer recording of a difference & \\
between paired films & $57(48)$ \\
Loss of tibiofemoral joint space (mm) & \\
2 & $14(12)$ \\
1 & $33(28)$ \\
0 & $51(43)$ \\
-1 & $19(16)$ \\
-2 & $2(2)$ \\
\hline
\end{tabular}

Table 5 Predictive value of scintigraphic findings at entry in relation to subsequent radiographic change and progression to an operation on the knee. Numbers of patients are shown

\begin{tabular}{lcccc}
\hline Scan at entry & $\begin{array}{c}\text { No radiographic } \\
\text { change }\end{array}$ & $\begin{array}{c}\text { Some radiographic } \\
\text { change }\end{array}$ & $\begin{array}{c}\text { Loss of } \geqslant 2 \mathrm{~mm} \\
\text { of joint space }\end{array}$ & Operation \\
\hline $\begin{array}{l}\text { No abnormality } \\
\text { Late phase/one compartment }\end{array}$ & 40 & 15 & 0 & 0 \\
$\begin{array}{l}\text { abnormality only } \\
\text { ate plus perfusion phase }\end{array}$ & 33 & 21 & 11 & 6 \\
\hline
\end{tabular}

The main purpose of the study was to assess the ability of scan abnormalities at entry to predict subsequent progression to an operation or loss of joint space. Table 5 gives the relation between a positive (abnormal) scan at entry, and these defined outcome measures. Of the one hundred and forty two knees assessed, $36(25 \%)$ progressed in the way defined, $22(15 \%)$ needing an operation and a further $14(10 \%)$ showing joint space narrowing of $2 \mathrm{~mm}$ or more. None of the 55 knees that had no scan abnormality at entry progressed, and no radiographic change could be detected in $40(73 \%)$ of these knees. In contrast, defined progression or some form of radiographic change was seen in $52(60 \%)$ of the knees with a scan abnormality at entry. The degree of scan abnormality has been further divided into those with a late phase abnormality only, and the more severe group with abnormal uptake of isotope in the perfusion phase as well as the bone phase of the scan. As shown in table 5, most knees needing an operation during the study period had the more severe scan abnormality at entry, and only four (13\%) of 32 knees with this finding did not change in some way. These data have also been used to assess the discriminatory power of the scan in predicting progression, defined as either needing an operation or joint space narrowing of $2 \mathrm{~mm}$ or more. The scan has high negative predictive value $(100 \%)$, but low positive predictive value (39\%).

Put simply, all patients who progressed had a positive scan, but almost half of the patients who did not progress also had positive scans.

The data have also been examined to search for other potential predictors of change. The ability of a wide variety of demographic, clinical, and radiographic variables to predict subsequent change in radiographs or the need for an operation was explored (table 6 ). The strongest positive relation to emerge was the association between severity of pain at entry and a subsequent operation on the knee $(p \leqslant 0.001)$. Other entry variables that achieved highly significant correlations with outcome were the presence of crepitus, joint swelling, and instability of the knee. Demographic data, including patient age, sex, duration of symptoms, and body mass index, had little or no effect on outcome. Variables that relate to rare events were not used in this analysis.

It has been reported previously that a positive scan correlates with some cross

Table 6 Associations sought to detect predictors of the outcome in individual knee joints

\begin{tabular}{|c|c|c|c|c|}
\hline $\begin{array}{l}\text { Significance } \\
(\%)\end{array}$ & Operation & Change in pain & Radiographic change & $\begin{array}{l}\text { Foint space } \\
\text { change }\end{array}$ \\
\hline $0 \cdot 1$ & $\begin{array}{l}\text { Knee pain } \\
\text { Crepitus } \\
\text { Bony swelling } \\
\text { Soft tissue } \\
\text { Swelling } \\
\text { Instability } \\
\text { Interbone distance }\end{array}$ & $\begin{array}{l}\text { Knee pain } \\
\text { Bony swelling } \\
\text { Soft tissue swelling } \\
\text { Instability }\end{array}$ & $\begin{array}{l}\text { Crepitus } \\
\text { Bony swelling } \\
\text { Number of compartments affected }\end{array}$ & Instability \\
\hline 1 & $\mathrm{BMI}^{\star}$ & $\begin{array}{l}\text { Crepitus } \\
\text { Interbone distance }\end{array}$ & $\begin{array}{l}\text { Soft tissue } \\
\text { Swelling } \\
\text { Interbone distance }\end{array}$ & Crepitus \\
\hline 5 & & $\begin{array}{l}\text { Sex } \\
\text { Number of compartments affected }\end{array}$ & $\begin{array}{l}\text { Knee pain } \\
\mathrm{BMI}^{\star}\end{array}$ & \\
\hline
\end{tabular}


sectional radiographic and clinical findings, including pain and osteophytosis. ${ }^{13}$ These data were therefore examined to ascertain how much of the scan abnormality could be predicted by other entry data and whether the predictive value of the scan could be accounted for by other variables. An abnormal scan showed a positive correlation with osteophyte score and the presence of sclerosis on the radiographs, but not with interbone distance. Using discriminant analysis, radiographic variables could only account for $63 \%$ of the scan abnormality. A positive scan also correlated with pain and stiffness at entry, but all clinical variables achieved a success rate of only $63 \%$ in predicting scan abnormalities. Using clinical and radiographic variables together, the discriminant analysis achieved a success rate of $76 \%$ in prediction of scan abnormalities. Pain severity at entry and the other clinical and radiographic variables which correlate with the scan abnormalities correlate strongly with subsequent surgical intervention $(75 \%)$; however, as shown in table 6 , most of these variables do not predict subsequent progression of joint space narrowing $\left(r^{2}=8 \cdot 5 \%\right.$ using all clinical and radiographic variables).

Finally, the data relating scan abnormalities at entry to progression (an operation or joint space narrowing) were reanalysed using left knees only, in case the two knees of a subject are not operating as independent variables. Similar values for the positive $(100 \%)$ and negative $(29.6 \%)$ value of the scan were obtained and the positive predictive ability remained significant $(p=0 \cdot 005)$.

\section{Discussion}

This study considered the outcome, over a five year period, of a group of patients with established symptomatic OA of the knee joint who were referred to a rheumatology unit for diagnosis or treatment. At entry these patients were similar to those described in other hospital based series ${ }^{3}{ }^{4}$ 19: they were predominantly women in their early $60 \mathrm{~s}$, and had a history of many years of symptoms before hospital referral. Radiographic changes varied from mild to severe destructive changes in the knees, most having well established unilateral or bilateral evidence of joint damage due to OA. This is consistent with a slow evolution of the disease after the menopause and the relatively late development of sufficient symptoms or disability to warrant intervention. In spite of the fact that huge numbers of such patients seek medical help, however, relatively little is known about their disease outcome, and almost nothing can be predicted about their prognosis. In such a common disorder, ${ }^{1}$ responsible for such a burden of pain and disability $^{2}$ as well as extensive use of medical resources $^{20}$ it is clearly important to try to ascertain prognostic factors and determinants of a poor outcome.

This investigation centred on the changes in individual knee joints rather than individual patients. The patients reported a range of changes in their pain and function. There was a general decrease in walking ability but less change in pain, many patients reporting some improvement. It is difficult to interpret these data, however; the five year time period, with its general effect on other systems and changes in social circumstances, as well as the problem of remembering what it was like five years ago, mean that little weight can be attached to such information. Our concern therefore, was to obtain as much objective information as possible about changes in each knee joint and to relate this to standardised data collected at entry. We did not choose to compare findings on physical examination of the knee joint five years apart for two reasons. First, the examiner who obtained the entry data was not available, so a different observer, probably using different techniques, would have been used; secondly, we know that the reproducibility of many of these findings is not great, even if the same observers, using the same techniques, obtain the information. ${ }^{21} 22$ In contrast, radiographic analysis allowed us to use the same observer and a set of observations known to have reasonably good reproducibility. ${ }^{14}$ We also took exceptional care to blind the observer to date order and patient identification, and all film reporting was carried out during a single week. Our other main outcome measure was an operation on the knee; surgical decisions were made in the normal way and those making the decisions were unaware of the enrolment of the patient in this study. There is little risk of inaccuracy about this outcome measure. Twenty two knees of 15 patients were operated on over the five years, leaving eight contralateral, unoperated knees in these patients. We decided to omit these from analysis because of the possible effect of an operation on one knee on the outcome of the other. We still had 22 operated knees and 120 unoperated knees to analyse for predictors of outcome, providing the study with considerable power. The omission of rare events from the analysis further strengthens the power of the study.

The main hypothesis tested by this study was that scan abnormalities would predict subsequent outcome of OA of the knee. The data support this hypothesis. A normal scan proved to be a powerful negative predictor; in other words, change over the subsequent five years was extremely unlikely if the entry scan was normal. In addition, a positive scan was a significant positive predictor of subsequent loss of joint space in OA of the knee. Data analysis showed that a significant proportion of the scan abnormalities at entry could not be accounted for by other variables, indicating that the scan is contributing independent information about the status of the knee joint, and that scan positivity is not simply a reflection of disease severity. Furthermore, the finding remains highly significant if only left knees are considered, negating the possible confounding effects of two knees not acting as independent variables. Furthermore, no combination of demographic, clinical, or radiographic variables had the same predictive power for radiographic change as was found for scan abnormalities. The ability of a positive bone 
scan to predict subsequent joint space narrowing is the significant new finding to emerge from this study.

The isotope used was technetium-99m labelled methylene diphosphonate, a standard bone scanning agent. ${ }^{23}$ It is preferentially retained in areas of bone pathology associated with increased turnover. ${ }^{24}$ Previous work on bone scans in OA of the knee has shown that they are sensitive to pathology ${ }^{25}$ and that the most common pattern of isotope retention is in the subchondral bone in the 'late' phase, when the scan is most likely to reflect bone activity. ${ }^{13}{ }^{24}{ }^{26}$ It has also been shown that bone scans can have predictive value in the evolution of interphalangeal OA of the hand. ${ }^{11}{ }^{12}$ This study indicates that progression of joint space narrowing, a surrogate for cartilage destruction, is unlikely in the absence of isotope retention in subchondral bone. It also indicates that some joints with OA are in an active phase, whereas others are inactive, or stable, as hypothesised previously. ${ }^{27}$ Why should a bone scan predict subsequent joint space narrowing? It may be that if the OA process is active in cartilage, leading to further destruction, the subchondral bone is also metabolically abnormal, either in response to or together with whatever drives the cartilage destruction An alternative more radical explanation would be that turnover drives progression of $\mathrm{OA}$, and that the cartilage is the innocent bystander. Whatever the explanation proves to be, the findings emphasise the potential importance of subchondral bone turnover in the pathogenesis of OA.

Bone scans had more predictive value for change in the joint space than for changes in the bone itself, such as osteophytosis or subchondral sclerosis. This may simply reflect the lack of sensitivity of the radiographic methods used in detecting bony changes, however. The use of a simple three point scale for osteophytes and an 'on-off' recording of sclerosis gives little scope for detecting change. In addition, it is known that radiographs are insensitive to bone pathology in $\mathrm{OA}$ of the knee. $^{28}$

The data were examined for other predictors of outcome and a number of statistically significant associations emerged, in part because of the interrelationships between many of the variables. The strongest independent predictor of outcome, other than scan positivity, was the severity of pain at entry, which predicted an operation. This is not a surprising finding in view of the fact that pain is used as one of the main indications to operate on the knee joint.

Other negative findings in this study may prove to be as important as the positive findings. We were unable to detect any effect of age, sex, obesity, or duration of symptoms on the subsequent change and several other clinical variables-including instability - were only weakly related to outcome. This finding contrasts with that of Schouten et $a l^{29}$ who reported that age and weight were predictors of radiographic prognosis in a community based study of OA of the knee. Our negative findings may be explained by the relatively low power of our study to establish negative predictors, however. It can be concluded from our data that OA of the knee does not necessarily progress in an obese patient, or in the presence of instability, but we cannot rule out some influence of these variables on the progression of $\mathrm{OA}$ in general. Conclusions from our study are also limited by its relatively short duration (five years only represents about $40 \%$ of the total symptom duration of our patients), and small number of patients. The findings, study size, and duration, however, are large enough to be of relevance to clinical practice and clinical trials, and the study probably has greater power than most previous reports on the determinants of progression in $\mathrm{OA}$.

The clinical significance of this study deserves further comment. There appear to be two relevant findings. First, OA of the knee can do relatively well over a five year time period, even if the initial radiographic and clinical findings indicate severe joint damage, irrespective of patient age, sex, disease duration, and weight. It is therefore inappropriate to give patients too pessimistic a picture of outcome. Secondly, a normal bone scan could provide a clinician with confidence that the disorder is unlikely to progress over the next few years. Although bone scans, which are relatively invasive and expensive, cannot be recommended in routine patient management, particularly as their positive predictive value is limited, they may be useful in selected patients where it is particularly important to know whether disease progression is likely.

We thank Drs Fiona McCrae and Iain Watt for their earlier work on the entry data, the Arthritis and Rheumatism Council fo financial support, and Mrs Sara Browning for secretarial help.

1 Felson D T. The epidemiology of hip and knee osteoarthritis. Epidemiol Rev 1988; 10: 1-28.

2 Laurence R C, Hochberg M C, Kelsey J L, et al. Estimate of the prevalence of selected arthritic and musculoskeleta disease in the United States 1989. F Rheumatol 1989; 16 427-41.

3 Massardo L, Watt I, Cushnaghan J, Dieppe P. Osteoarthritis of the knee joint: an eight year prospective study. $A n n$ Rheum Dis 1989; 48: 893-7.

4 Spector T D, Dacre J E, Harris P A, Huskisson E C. Radiological progression of osteoarthritis: an 11 year follow up study of the knee. Ann Rheum Dis 1992; 51: follow up

5 Harris W H, Sledge C B. Total hip and knee replacement. N Engl f Med 1990; 323: 725-31.

6 Harris W H, Sledge C B. Total hip and knee replacement. $N$ Engl f Med 1990; 323: 801-7.

7 Bullough P G. The pathophysiology of osteoarthritis. In Russell R G G, Dieppe P A, eds. Osteoarthritis: curren research and prospects for pharmacological intervention. London: IBC Technical Services, 1991: 24-33.

8 Dieppe P. Osteoarthritis: clinical and research perspective. Br F Rheumatol 1991; 30 (suppl 1): 1-4.

9 Dieppe P, Cushnaghan J. The natural course and prognosis of osteoarthritis. In: Moskowitz R, Howell D J Goldberg V M, Mankin J H, eds. Diagnosis and medical surgical management Company, 1992: 399-412.

10 Radin E L, Abernethy P J, Townsend P M, Rose R M. The role of bone changes in the degeneration of articular cartilage in osteoarthritis. Acta Orthopead Belg 1978; 44: 55-63.

11 Hutton C W, Higgs E R, Jacobson P C, Watt I Dieppe P A. ${ }^{99 \mathrm{~m} T \mathrm{~T}}$ HMDP bone scanning in generalised arthritis. II. The four hour bone scan image predicts radiographic change. Ann Rheum Dis 1986; 45: 622-6.

12 Macfarlane D G, Buckland Wright J C, Emery P, Fogelman I, Clark B, Lynch J. Comparison of clinical, Fogelman I, Clark B, Lynch J. Comparison of clinical, radionuclide, and radiographic features of oste

13 McCrae F, Shouls J, Dieppe P, Watt I. Scintigraphic assessment of osteoarthritis of the knee joint. Ann Rheum Dis 1992; 51: 938-42. 
14 Cooper C, Cushnaghan J, Kirwan J R, et al. Radiographic assessment of the knee joint in osteoarthritis. Ann Rheum Dis 1992; 51: 80-2.

15 Lequesne M, Glimet T, Massé J P, Orvain J. Speed of the joint space narrowing (JSN) in primary medial osteoarthritis of the knee (OAK) over 3-5 years [abstract]. Osteoarthritis of the knee (OAK) 0ver 3 -

16 Clarke G M, Cooke D. A basic course in statistics. 2nd ed. London: Edward Arnold, 1983.

17 Ryan B F, Jointer B L, Ryan T A. Minitab handbook. 2nd ed. Boston: PWS-Kent, 1991

18 Garrow J S, Webster J. Quetelet's index $\left(\mathrm{W} / \mathrm{H}^{2}\right)$ as a measure of fatness. Int $\mathcal{f}$ Obes 1985; 9: 147-53.

19 Huskisson E C, Dieppe P A, Tucker A K. Another look at osteoarthritis. Ann Rheum Dis 1979; 38: 423-8.

20 Hadler N M. Osteoarthritis as a public health problem. Clin Rheum Dis 1985; 11: 175-85.

21 Cushnaghan J, Cooper C, Dieppe P, Kirwan J, McAlindon T, McCrae F. Clinical assessment of osteo990; 49: 768-70.

22 Jones A, Hopkinson N, Pattrick M, Berman P, Doherty M. Evaluation of a method for clinically assessing osteoarthritis of the knee. Ann Rheum Dis 1992; 51: 243-5.

23 Hoffer P B, Genant H K. Radionuclide joint imaging. Semin Nucl Med 1976; 6: 121-37.

24 Fogelman I ${ }^{99 m}$ Tc diphosphonate uptake mechanism on bone. In: Fogelman I, ed. Bone scanning in clinical practice. berlin: Springer, 7-17.

25 Thomas R H, Resnick D, Alazrake N P, et al. Compartmental evaluation of osteoarthritis of the knee. A comparative study of available diagnostic modalities. Radiology 1975; 116: 585-94.

26 Christiansen S B. Osteoarthrosis: changes in bone, cartilage and synovial membrane in relation to bone scintigraphy. Acta Orthop Scand 1985; 56 (suppl 214): 1-43.

27 Dieppe P. Osteoarthritis: clinical and research perspective. Br f Rheumatol 1991; 30 (suppl 1): 1-4.

28 Rogers J, Watt I, Dieppe P. A comparison of the visual and radiographic detection of bony changes at the knee joint. BMF 1990; 300: 367-8.

29 Schouten J, Ouweland F A, Valkenberg H. A 12 year follow up study in the general population on prognostic factors of cartilage loss in osteoarthritis of the knee. Ann Rheum Dis 1992; 51: 932-7. 